\title{
0 método no centro: relatos de campo de uma pesquisa psicossocial de perspectiva etnográfica
}

\author{
Cris Fernández Andrada*
}

Pontifícia Universidade Católica de São Paulo. São Paulo, SP, Brasil

\begin{abstract}
Resumo: $\mathrm{O}$ artigo tem por objetivo debater alguns efeitos do uso do referencial teórico-metodológico da etnografia em pesquisas de psicologia social, especialmente a etnografia multissituada. Para isso, toma o caso de uma pesquisa de doutorado desenvolvida nessa interface e discute parte de seus problemas e imprevistos, bem como as escolhas e recursos utilizados para enfrentá-los. Também procura apresentar os critérios que orientaram o desenho da pesquisa de modo geral.
\end{abstract}

Palavras-chave: psicologia social, método etnográfico, etnografia multissituada, metodologia, trabalho de campo.

Esquece-se, porém, de que frequentemente os meios transformam o fim; que todo fim tem implícitos os seus próprios meios. Se se quer realizar um fim com meios que the são heterogêneos não se consegue nunca fazê-los.

Agnes Heller

\section{Traçando rotas ou aquilo que o campo pede ${ }^{1}$}

Por basear-se na observação e experimentação prolongada da vida onde ela acontece (Sato \& Souza, 2001), o enfoque etnográfico tem guiado cada vez mais estudos nas ciências sociais, ampliando a trilha aberta em meio aos paradigmas metodológicos tradicionais (Andrada, 2010). O objetivo deste texto é debater alguns feitos do uso do referencial teórico-metodológico da etnografia em pesquisas psicossociais, especialmente a etnografia multissituada, por meio da apresentação de relatos de campo de uma investigação desenvolvida nessa interface. Propomos, com isso, discutir escolhas e recursos utilizados na lide com o problema central da pesquisa e com imprevistos surgidos no decurso do campo. Não é nosso objetivo, portanto, tecer análises teóricas gerais a respeito do tema.

Para tratar questões de método, é comum recorrer à etimologia do termo que remete às ideias de meio e de escolha ${ }^{2}$. Em geral, o expediente é utilizado para reiterar que não há (ou não deveria haver) lugar para absolutismos nesse tocante, mas uma permanente e sensível atenção ética (Becker, 1999; Schmidt, 2008). Ou seja, adotar um método

* Endereço para correspondência: andrada@usp.br

1 Este texto é fruto de estudos realizados durante pesquisa de doutorado. Contou com aportes das disciplinas $A$ dimensão cultural das práticas urbanas, ministrada pelo Prof. Dr. José Guilherme Magnani (FFLCH-USP) e $O$ trabalho de campo na pesquisa qualitativa em Psicologia, ministrada pelas Prof $f^{\text {as }}$. Dras. Leny Sato e Marilene Proença (IP-USP), em 2009 e 2010, respectivamente. Outro artigo sobre o tema foi publicado na revista Ponto Urbe, do Núcleo de Antropologia Urbana da USP (Andrada, 2010).

2 "A palavra método origina-se do grego methodos; composta por meta: meio; e hodos: via, caminho; entre outras acepções” (Dicionário etimológico, 2008). de pesquisa é traçar um trajeto entre outros para alcançar um determinado objetivo. Não haverá, pois, "o melhor método", senão em relação a um determinado fim. Ecléa Bosi (2003, p. 55) resumiu impecavelmente a questão: "no tocante às técnicas de pesquisa, estas devem ser adequadas ao objeto: é a lei de ouro. Não conheço outra".

Tomadas por essas considerações, e apoiadas em experiências anteriores no campo da economia solidária, propusemos uma pesquisa de doutorado com o objetivo de compreender as relações entre trabalho e política no cotidiano de uma rede autogerida, a Justa Trama (Andrada, 2013; Andrada \& Sato, 2014) $)^{3}$.

Para discutir escolhas metodológicas faz-se necessário, portanto, apresentar os objetivos e o fenômeno que se quer conhecer. A Justa Trama foi proposta em 2005 por trabalhadoras da economia solidária (Singer, 2002), a maioria mulheres de baixa renda, como uma cooperativa de segundo grau ${ }^{4}$. A sede localiza-se em Porto Alegre (RS), mas a rede congrega cerca de seiscentas pessoas de sete coletivos econômicos diversos de todas as regiões do país. Juntos, abarcam grande parte da cadeia produtiva do algodão agroecológico. No arranjo dessa rede é possível encontrar trabalhadoras e trabalhadores dos meios rural e urbano, de diversos setores da economia, de atividades como agricultura, indústria e artesanato. Em conjunto, fabricam insumos fios, tecidos e adereços - que resultam em roupas, bolsas e brinquedos de algodão agroecológico (Andrada \& Sato, 2014) 5

3 A pesquisa foi desenvolvida no Programa de Pós-Graduação em Psicologia Social da Universidade de São Paulo, sob orientação de Leny Sato. Recebeu Menção Honrosa no Prêmio Tese Destaque USP 2014 (categoria ciências humanas) e Prêmio ABRAPSO 2013 - categoria tese (doutorado), da Associação Brasileira de Psicologia Social.

4 Referimo-nos às integrantes da Justa Trama no gênero feminino uma vez que o coletivo é composto majoritariamente por mulheres.

5 Para mais informações, consultar: http://www.justatrama.com.br. Recomendamos vivamente ainda a leitura do livro sobre a história de 


\section{Primeiro itinerário: da psicologia para a antropologia}

Definidos campo e objetivo da pesquisa, dirigimo-nos à antropologia para estudar detidamente o método etnográfico, que já havia significado um oriente importante para investigar processos da vida cotidiana, caso desta investigação (Andrada, $2009)^{6}$. Os ecos do ali vivido - leituras e debates - foram tantos que por vezes estranhamos nosso território (a psicologia social) e nos sentimos em casa em solo estrangeiro (a antropologia). Mais tarde, no entanto, cresceu a necessidade de retornar e encontrar nas linhas do texto psicossocial as pontes que nos levaram ao encontro daqueles aspectos que mais fascínio exerceram em terras antropológicas. Nesse ímpeto, foi reconfortante ler Mary Jane Spink (2007) e Peter Spink (2008), por recuperarem, na memória da psicologia social, experiências autóctones de observação no cotidiano.

Cabe apontar, porém, o que encontramos de valioso na antropologia. A possibilidade larga e espontânea, em geral conferida pela disciplina, de apreciar a diferença tal-qual, de não imputar exigências de enquadre em algo que não lhe é próprio, exerceu grande encanto. Trata-se de um aporte clássico da área às demais ciências sociais. Se no interior da antropologia há pluralidade e dissensos, também se localiza ali, em geral, esse convite ao encontro com a diferença sem extraí-la de seu sítio original, sem violentá-la com questões alheias a ela, que a dilaceram porque não lhe cabem.

Aprendemos também com os colegas antropólogos que uma realidade é cultural porque foi construída e, por isso, guarda em seu solo as nascentes de seus sentidos, feitos e refeitos por seus habitantes nas lides uns com os outros e com esse solo ao longo dos tempos. Para alcançar esses sentidos, eles ensinam, é preciso praticar uma reserva - um retiro que nos coloque em algum ponto entre o nosso lugar e o do outro - e ali permanecer, suspenso entre duas culturas (DaMatta, 1978). Permanecer o tempo que pede a experiência, dedicar-se a ela de perto e de dentro (Magnani, 2009), e então retornar ao nosso ponto de partida e estabelecer os diálogos entre "o lá e o cá" - entre o experience-near e o experience-distant de Geertz (1999).

Com efeito, essa era uma preocupação éticometodológica que em grande parte justificou a eleição do método etnográfico (além da adequação ao objeto): queríamos evitar dirigir-nos às trabalhadoras da Justa Trama portando questões postiças a elas, em nome da pesquisa. De modo simples, gostaríamos que a experiência permitisse um encontro respeitoso entre diferentes - que afinal somos - e a construção de um sentido compartilhado (Schmidt, 2008).

Em pesquisa anterior, realizada com as costureiras da Cooperativa Univens (Andrada, 2009), notamos que a abertura propiciada pelo método etnográfico permitiu o alargamento das possibilidades do vivido de modo a contemplar boa parte das idiossincrasias e interesses de ambos os lados.

lutas do coletivo, escrito por uma de suas protagonistas, Nelsa Nespolo (2014).

6 As pesquisas mencionadas também contaram com a orientação da Professora Leny Sato, que há tempo estuda a abordagem etnográfica em interface com a psicologia social do trabalho (Sato \&Souza, 2001).
E assim as questões de método foram ganhando centralidade para nós. Em outros termos, o modo como significamos o trabalho de campo na afluência das perspectivas psicossocial e etnográfica: como fruto de relações interpessoais e escolhas cotidianas travadas no decurso dessas relações, entre pesquisadores/as e pessoas da situação pesquisada (Sato \& Souza, 2001; Schmidt, 2008).

Certamente não se trata de um processo fácil ou fluido. Nesses estudos, muitas vezes foi necessário diminuir o passo, parar ou mesmo retroceder para reconversar os termos da pesquisa. Negociações, recontratos, malentendidos, não-entendidos. Tudo conjugado no plural, como é próprio das etnografias e pesquisas participantes (Becker, 1999; Sato \& Souza, 2001). E, frisemos, essa intensa negociação em campo não se deveu apenas ao método, mas a uma característica intrínseca da experiência pesquisada: a exigência de autonomia e participação política de seus sujeitos, trabalhadoras com apreço pela autogestão em todas as relações, o que inclui pesquisadores/as. Também por isso, se tivéssemos nos dirigido a elas com uma prancheta de questionários debaixo do braço, o desfecho da pesquisa teria sido outro, provavelmente mais opaco (também um modo de referir a adequação objeto-método) ${ }^{7}$.

Sabe-se ainda que o método etnográfico caracteriza-se por ser mais exigente com o/a pesquisador/a (Sato \& Souza, 2001). Ela ou ele certamente demorará mais em campo, quando comparado a outros métodos. Sentir-se-á perdido, deslocado, lançado ao inusitado da vida cotidiana do lugar - e pior, sem nada saber sobre seus códigos e léxicos. Não à toa, questões corriqueiras ganham enorme importância nos primeiros dias em campo: o que comer ou vestir, onde guardar os pertences etc. (Sato \& Souza, 2001). Como observa Roberto DaMatta (1978, p. 24):

a oscilação do pêndulo da existência para tais questões - onde vou dormir, comer, viver - não é nada agradável. Especialmente quando nosso treinamento tende a ser excessivamente verbal e teórico, ou quando somos socializados numa cultura que ensina sistematicamente o conformismo, esse filho da autoridade com a generalidade, a lei e a regra.

Também terá que se desfazer de qualquer resquício de autoridade - não importa quem o pesquisador seja, que títulos porte, chegará em terra estrangeira sem sobrenome ou apostos, a não ser o de forasteiro. E se vir a alcançar algum reconhecimento ali, certamente terá sido construído na relação com as pessoas do lugar, que nada ou pouco sabem dele de antemão, e que, na melhor das hipóteses, tiveram com ele de início uma complacência humano-genérica, como bem aponta Cláudia Fonseca (1999, pp. 64-65):

Nesta situação, o pesquisador, um intruso mais ou menos tolerado no grupo, não nutre mais a ilusão

\footnotetext{
7 Não será possível tratar a fundo do rito de passagem e do processo de negociação da pesquisa neste texto. Sugerimos a leitura da seção dedicada a esses temas na tese resultante da pesquisa (Andrada, 2013, p. 58).
} 
de estar "em controle da situação". É justamente aqui, quando seu mal-estar, sua incompetência nas linguagens locais o obriga a reconhecer dinâmicas sociais que não domina bem, que o antropólogo sente que está chegando a algum lugar. ... Quando nossos "nativos" começam finalmente a sentir-se em casa na nossa presença, zombam de nós ou até nos ignoram, aí passamos além dos diálogos "para inglês ver". Ninguém nega que somos parte da realidade que pesquisamos.

\section{$\mathrm{Na}$ fronteira: encontros e tensões entre os enfoques}

Não pretendemos explorar a fundo as relações entre as perspectivas psicossocial e etnográfica; já o fizemos em trabalhos anteriores (Andrada, 2010). Destacaremos apenas alguns aspectos relevantes para a presente discussão. O primeiro deles é a pluralidade de dissensos existentes no interior de cada um desses territórios. Em outras palavras, há muitas psicologias sociais (Farr, 1998) e muitas antropologias (Oliveira, 2000). E, por conseguinte, divergentes modos de operar com os temas de método em cada uma delas. Nosso olhar se detém no encontro entre leituras específicas de ambas as áreas e, nesse sentido, é limitado.

A psicologia social da qual partimos joga luz sobre a tensão identitária que constitui a disciplina e ali se mantém: a intangível ponte indivíduo-sociedade ou as indissociáveis tramas que enlaçam e dialeticamente constituem pessoas e mundo (Andrada, 2010). Para apresentá-la de modo breve e preciso, servimo-nos do bonito texto de Arakcy Martins Rodrigues (1978, p. 15):

Se, por certos períodos, tendi para uma explicação intra-subjetiva do homem, se em outros, o peso da percepção das determinações sociais me levou praticamente a abdicar da psicologia, como ocorreu com inúmeros estudiosos de psicologia social, procurei aqui um equilíbrio na busca de uma explicação interativa entre o homem e os processos sociais historicamente dados. . . . Sei ainda que ocupo um lugar de fronteira, reivindicado por várias disciplinas.

Gonçalves Filho (1998, p. 11) também recorre à noção de fronteira para situar o enfoque psicossocial:

Esta disciplina de fronteira, a psicologia social, caracteriza-se não pela consideração do indivíduo, pela focalização da subjetividade no homem separado, mas pela exigência de encontrar o homem na cidade, o homem no meio dos homens, a subjetividade como aparição singular, vertical, no campo intersubjetivo e horizontal das experiências. . . Os temas da psicologia social, justamente, incidem sobre problemas intermediários, difíceis de considerar apenas pelo lado do indivíduo ou apenas pelo lado da sociedade.
Para ilustrar a proximidade entre pressupostos das vertentes da psicologia social e da antropologia aqui discutidas, vejamos uma definição do método etnográfico advinda da própria antropologia. Em texto destinado a discutir aproximações problemáticas de outras áreas com esse enfoque, Cláudia Fonseca (1999, p. 59) assim o define: "o método etnográfico é visto como o encontro tenso entre o individualismo metodológico (que tende para a sacralização do indivíduo) e a perspectiva sociológica (que tende para a reificação do social)".

Falamos aqui de uma espécie de dobradura, ou seja, da sobreposição de duas fronteiras: aquela que constitui a própria psicologia social, reconhecida como área de fronteira em si, e aquela resultante de seu encontro com a antropologia especificamente. Ou seja, se há algo que podemos demarcar sobre essa intersecção é sua identidade fronteiriça. Para Boaventura de Sousa Santos, fronteiras podem ser utilizadas para explicar o que separa, mas também o que une: está assente tanto em limites como na sua transgressão (Santos, 2002).

E, embora não seja nosso objetivo, devemos reconhecer as múltiplas tensões e diferenças entre as disciplinas, que são vizinhas, mas não se confundem. É preciso distinguir as especificidades entre os enfoques psicossocial e etnográfico e os limites da aproximação entre eles, sem incorrer, no entanto, em posturas patrimonialistas que cerceiam a circulação de saberes e constrangem a primazia do objeto. Entretanto, sabidamente, entre áreas fronteiriças há mais intercâmbio, como também a necessidade periódica de redemarcar as linhas que configuram os territórios e que lhes conferem identidade.

Por exemplo, boa parte dos problemas identificados por estudiosos na aproximação desses campos advém de riscos atribuídos às práticas interdisciplinares em geral. Riscos questionáveis, como veremos. Um deles é o uso instrumental do método etnográfico em pesquisas psicológicas sem o cuidado de situar devidamente os sujeitos em seus contextos, como aponta Fonseca (1999, p. 62):

Resumimos o problema assim. Por causa do valor central do indivíduo em nossa sociedade .... existe entre nossos estudantes uma forte tendência a isolar o indivíduo de seu grupo social. A "pesquisa de campo" se reduz a entrevistas quase terapêuticas entre apenas duas pessoas. Existem ramos científicos (da psicologia e das ciências cognitivas) que fornecem orientações para a análise de tal situação. ... Mas no clima iconoclasta atual - essas abordagens são rejeitadas por boa parte dos antigos adeptos em prol de algo mais "aberto": o método etnográfico. O problema é que a etnografia não é tão aberta assim, pois faz parte das ciências sociais e exige o enquadramento social (político e histórico) do comportamento humano.

Ora, a exigência atribuída à etnografia por Fonseca (1999), qual seja, ler o comportamento humano segundo os enquadres de seus contextos político e histórico, também é 
premissa da psicologia social que praticamos. Obras basais de psicólogas sociais brasileiras como Arakcy Martins Rodrigues (1978) e Sylvia Leser de Mello (1988) são exemplos disso.

Em trabalho anterior (Andrada, 2010), discutimos pontos de contato entre os enfoques psicossocial e etnográfico por meio do exame de dois aspectos: a) o peculiar deslocamento que ambos enfoques exigem dos/as pesquisadores/as na direção do Outro; b) a consideração da pesquisa como "processo de convivência entre pessoas" (Sato \& Souza, 2001), para além da posição sujeito-objeto.

Grifamos aqui um ponto em particular, referente ao último aspecto. Ao postular o cotidiano como "tudo o que temos", Peter Spink (2008, p. 70) recupera "a noção da psicologia social como prática social, de conversa e de debate, de uma inserção horizontal do pesquisador nos encontros diários", situados em lugares ou micro-lugares. O antropólogo Vagner da Silva (2006, p. 184, grifos nossos) aponta na mesma direção:

Assim, uma das respostas possíveis à pergunta de Malinowski sobre "qual é, então, esta magia do etnógrafo, com a qual ele consegue evocar o verdadeiro espírito dos nativos, numa 'visão autêntica' da vida tribal?", é a de que consiste numa "autoilusão" que isto seja plenamente possível, pois não existe, percebemos cada vez mais, um "verdadeiro" espírito dos nativos nem uma "visão autêntica" da vida dos grupos. Ambas são construções realizadas a partir da convivência entre pessoas que se observam e se interpretam mutuamente, não sendo possível haver "palavras finais" além das que são pronunciadas continuamente no fluxo ininterrupto do diálogo cultural.

Nesse sentido, e desde a psicologia social, Sato \& Souza (2001) destacam que não apenas técnicas e rigores metodológicos serão os lastros de uma boa pesquisa, mas a qualidade e a ética das relações estabelecidas em campo entre pesquisador/a e pessoas da situação pesquisada. Assim, para que o encontro entre sujeitos diferentes, no enquadre de uma pesquisa, possa efetivamente produzir conhecimentos e sentidos compartilhados de modo não violento ou fetichizado (o que apenas afirmaria lugares e relações de poder), deve-se zelar não somente os diálogos e proximidades, mas também os silêncios e recuos, em termos intersubjetivos.

\section{Os múltiplos deslocamentos da pesquisa: notas e reflexões de campo}

Nesta etapa, ou antes, nesta dimensão da pesquisa, eu não me encontro mais dialogando com índios de papel ou com diagramas simétricos, mas com pessoas. ... Estou, assim, submerso em um mundo que se situava, e depois da pesquisa volta a se situar, entre a realidade e o livro. ... É vivenciando esta fase que me dou conta (não sem susto) que estou entre dois fogos: a minha cultura e uma outra, o meu mundo e um outro. (DaMatta, 1978, p. 25, grifos nossos)

No projeto da pesquisa que tomamos como caso neste texto, lia-se a seguinte proposta, objetivamente cumprida:

estudo de caso baseado em ampla experiência etnográfica, composto por três etapas: 1) primeiros contatos com as trabalhadoras e apresentação da proposta; 2) viagens de campo aos coletivos integrantes da rede de cooperativas, localizados em 5 (cinco) estados do país; e 3) retorno a alguns deles para entrevistas semiestruturadas prolongadas com trabalhadoras escolhidas a partir das visitas realizadas.

Mas se não eram índios de papel, pareciam ainda um diagrama - desenho feito à mão livre, intenção traçada no silêncio da escrivaninha. Faltava sair, colocar os pés nas estradas que conduziriam às trabalhadoras deste coletivo que se esparrama pelo país. E ao encontrá-las, aí sim dar início a uma aventura comum, como diz Ecléa Bosi (2003). Porque esse grupo, que pulsa autogestão, seria certamente coautor - não do projeto, senão da experiência da pesquisa.

\section{Entre o planejado e o vivido: exigências do campo}

Os primeiros momentos vividos com as trabalhadoras inspiraram duas grandes mudanças na proposta da pesquisa: ajustes no foco da atenção e na rota das viagens em campo ${ }^{8}$. Debruçar-se sobre o cotidiano de uma rede organizada por um coletivo de mais de seiscentas trabalhadoras espalhado pelo país exigiu um contínuo esforço de foco e de síntese diante de tanto - tantas pessoas, grupos, contextos, diversidades. A complexidade do objeto deste caso aumentou o interesse e exigiu, de certa forma, mais trabalho sobre os temas de método.

Sobre o foco da atenção, foi preciso traduzir os objetivos da pesquisa em fenômenos cotidianos a perseguir em campo. Porque buscar por relações entre trabalho e politica podia ser um postulado teórico formalmente nítido, mas revelou-se duro e impalpável perante a plasticidade do cotidiano com as trabalhadoras. Tratamos então de compreender em campo como elas conciliam as demandas do trabalho e da gestão com aquelas alusivas à política, que estímulos e entraves encontram nesses processos e que recursos desenvolveram para operar com eles em condições

8 Sobre o tema, sugerimos a leitura do item da tese "O campo exige revisões" (Andrada, 2013, p. 106). 
tão adversas. Também queríamos saber mais sobre o processo histórico de organização da rede. Para isso, as entrevistas nos valeram mais que as observações etnográficas.

Também foi necessário rever a rota das viagens em meio aos trabalhos. A ideia inicial era seguir "a trilha do algodão", procedimento comum entre pesquisadores/as de cadeias produtivas. Nesse caso, a rota está predefinida pelo processo produtivo: primeiro vai-se aos coletivos responsáveis pelo plantio do algodão, depois à fábrica que o fia e tece etc. Mas após as primeiras viagens essa trilha pareceu uma abstração pouco condizente com o objeto - os processos políticos cotidianos da rede. Em lugar de visitar os grupos em separado, fazia mais sentido acompanhar os encontros entre eles - a agenda política da rede -, o que por vezes nos levou para longe dos espaços formais dos coletivos em missões pelo país e pelo exterior (Andrada \& Sato, 2014).

A seguir, uma síntese das principais atividades realizadas: onze incursões em regime de imersão etnográfica e seis entrevistas prolongadas. Trata-se de experiências de intenso convívio com trabalhadoras da rede, em cerca de dois anos e meio de trabalho de campo.

Cada incursão requereu trabalhos prévios e posteriores à sua realização. Uma série de contatos, leituras e levantamentos, particulares a cada localidade e grupo visitado era uma exigência para que as experiências de campo se desenvolvessem bem, disparando o processo de deslocamento antes mesmo da partida. Ao retornar era necessário desenrolar os fios do vivido, com os sentidos e saberes próprios daqueles lugares e pessoas: reler os registros feitos em pequenas cadernetas e transpô-los em versão ampliada ao diário de campo ${ }^{9}$. Em seguida, os agrupávamos em pré-categorias e, por fim, em categorias de sentido, a partir de repetidas leituras. Esse processo (escrita, leitura, re-escrita e re-leituras) foi um meio que encontramos de decantar o campo. Mais que uma técnica procedimental generalizadora, essa decantação refere-se a um processo de progressiva abstração do sentido vivido rumo ao narrado, e da subsequente extração dos insumos fundamentais da narrativa produzida, aqueles mais relacionados ao objeto da pesquisa. Em suma, buscávamos traçar ou evidenciar, entre uma viagem e outra, as próximas direções a seguir na pesquisa a partir da interpretação do vivido ${ }^{10}$

Esse trabalho nos fez recordar os apontamentos de Peter Spink (2003, p. 38) sobre ciência como uma modalidade narrativa:

Muito daquilo que chamamos de ciência, especialmente a ciência social e a psicologia social, é a re-textualização do outro; o re-narrar do já narrado. $\mathrm{O}$ re-narrar acadêmico é um narrar

9 A escolha por pequenas cadernetas para as notas de campo revelou-se importante. Era preciso um instrumento de fácil manuseio, que permitisse registros rápidos e em lugares diversos (em ônibus e vans, no balcão de um bar ou na calçada, sobre o colo). Sugerimos artigo de Magnani (1997) sobre o tema.

10 Sobre os resultados brutos da pesquisa: cada dia de incursão resultou em média em oito páginas de relato no diário. As seis entrevistas (cinco individuais, uma coletiva) somaram cerca de nove horas de gravação. de maneira escrita do narrar oral, da conversa, da visita, do material, da materialidade, dos achados e perdidos. ${ }^{11}$

\section{Entre conversas e entrevistas}

Em meio ao trabalho de campo da pesquisa cresceu a necessidade de conversar com algumas trabalhadoras mais detidamente, ressalte-se, nos contextos da experiência etnográfica e a partir do vivido nela. Ou seja, as entrevistas serviram como um recurso auxiliar para dirimir dúvidas e levantar questões que não haviam sido suficientemente elucidadas. Em especial, queríamos resgatar com elas aspectos sobre a história da rede, questões que comparecem no cotidiano mais como fundo que como figura e por isso são pouco tematizadas no presente.

Mais que entrevistas, convém chamá-las de conversas gravadas. Em alguns casos, representaram a continuidade e o aprofundamento de reflexões que vínhamos tendo com determinada trabalhadora. Em outros, a proposta de uma interlocução reservada, com uma organização prévia de temas (ainda que flexível), expandiu um canal até então tímido de comunicação, permitindo ter com algumas pessoas um contato mais acurado e sensível. Porém, também nesses casos servimo-nos do vivido com essas pessoas e reciprocamente as vivências posteriores às entrevistas beneficiaram-se do contato mais detido, de modo que a separação entre essas conversas e as demais experiências de campo não nos parece adequada.

A escolha das pessoas a serem entrevistadas seguiu critérios de representatividade, para garantir a escuta de trabalhadoras de vários coletivos, sócias fundadoras e recentes, integrantes da direção da rede, mas não apenas ele ${ }^{12}$. Elegemos também pessoas com quem tivemos contato mais significativo durante as incursões. Elaboramos um roteiro geral, enxuto e aberto, a partir dos objetivos da pesquisa e das observações etnográficas. Preparamos algumas questões pensando em cada entrevistada. Para isso, selecionamos passagens do diário de campo que tratassem de experiências vividas com ela sobre aspectos dos quais gostaríamos de saber mais. Dessa forma, viriam informados por vivências compartilhadas entre nós.

Algo notável nas entrevistas ou conversas foi o fato de poucas vezes recorrermos ao roteiro. Ou seja, pelo tanto que havíamos convivido, as entrevistadas sabiam mais sobre o que queríamos conhecer. Sem exageros, por vezes pareciam dominar melhor as questões da pesquisa: "você vai entender depois", disse Idalina ${ }^{13}$, uma vez. Ainda assim, conhecer as perguntas não quer dizer dominar as respostas. Para isso é necessário o encontro e o diálogo entre diferentes, além do

\footnotetext{
11 Peter Spink é sabidamente um bom leitor de Charles Taylor. Sobre o tema, recomendamos a leitura de seu Compréhension et ethnocentrisme.

12 Perguntamos às trabalhadoras se gostariam de ser identificadas neste texto e, em caso afirmativo, de que forma. Todas as pessoas optaram por serem identificadas por seus nomes próprios.

13 In memoriam.
} 
trabalho de interpretação do vivido, socialmente construído, já mencionados (Andrada \& Sato, 2014).

Ainda sobre as entrevistas, vale mencionar o processo de revisão delas que procuramos fazer com as pessoas entrevistadas. Já no convite para a atividade, propusemos o envio de uma cópia impressa da conversa transcrita (o que foi feito). Mas principalmente expressamos a vontade de rever com cada pessoa o texto final da entrevista, a partir de suas leituras e impressões, algo que já havíamos feito em trabalhos anteriores (Andrada, 2013). Esse processo ocorreu em alguns casos mais do que em outros e foi muito significativo para os resultados da pesquisa. Memória marcante dessa etapa foi receber em mãos as sugestões de revisão dos agricultores de Tauá, presentes na roda de conversa gravada em campo ${ }^{14}$.

\section{As viagens propriamente: deslocamentos e encontros inusitados}

Enduro de moto no sertão cearense; canja quente e banho frio no retiro das Irmãs Josefinas de Fortaleza; a van até Quixadá; e a parada para as cajuínas comunitárias. Em Pará de Minas, aula sobre moda no sindicato, pamonha paulista e cordeiro uruguaio, mas a hospitalidade era mineira - e das melhores. Ficamos num bonito sítio de familiares de um dos cooperados, com direito a suflê de piranha e provas de cachaça da terra. Um quarto para duas pessoas serviu a oito em Porto Velho, contando comigo: "é só separar as camas [dessas "box"] e deitar duas em cada!", resolveu uma das trabalhadoras. No banho improvisado, a calça da trilha na mata virou toalha. A beleza da Amazônia desconserta e a pesquisadora desavisada leva como souvenir uma queimadura de cipó-fogo. Uma pequena marca entre as tantas deixadas por viagens de campo tão ricas quanto diversas, como os coletivos da Justa Trama.

A intenção do parágrafo anterior foi fotográfica. Diante da tarefa de apresentar as viagens de campo e da impossibilidade de descrever a riqueza e a amplitude das diferenças entre elas, buscamos um modo de condensá-las por meio de retratos textuais ${ }^{15}$. Quisemos fazer como Roberto DaMatta (1978, pp. 26-27), trazer à luz "o outro lado" da pesquisa de campo:

os aspectos que aparecem nas anedotas e nas reuniões de antropologia [ou da psicologia], nos coquetéis e nos momentos menos formais. Nas estórias que elaboram de modo tragicômico um mal-entendido entre o pesquisador e o seu melhor informante, de como foi duro chegar até a aldeia, das diarréias, das dificuldades de conseguir comida e - muito mais importante - de como foi difícil

14 Esse processo ocorreu também com a tese. Trabalhadoras de diversos grupos aportaram importantes reflexões ao texto que, na medida do possível, procuramos incorporar com a devida referência.

15 Recorremos a fotografias propriamente ditas em meio à tese como um recurso ante o desafio de apresentar a Justa Trama, inspirada pelo trabalho de Leny Sato (2009). conseguir comer naquela aldeia do Brasil Central. Esses são os chamados aspectos românticos da disciplina, quando o pesquisador se vê obrigado a atuar como médico, cozinheiro, contador de histórias, mediador entre índios e funcionários da Funai, viajante solitário e até palhaço, lançando mão destes vários e insuspeitados papéis para poder bem realizar as rotinas que infalivelmente aprendeu na escola graduada.

É possível que a leitura desses relatos cause estranhamento pelo tom coloquial e por expor aspectos subjetivos das relações em campo. Se não acreditamos na neutralidade das ações humanas - posto que há sempre intencionalidades e interesses a motivá-las - quando se trata de pesquisa, consideramos um dever revelar não apenas objetivos e métodos, mas também as concepções políticofilosóficas que guiaram o/a pesquisador/a em campo. De certo modo, são elas que orientam a interpretação dos resultados do estudo (Becker, 1999; Heller, 2008). Spink (2003, p. 37) brinda com mais argumentos a seguir: "lugares, eventos, pessoas, rostos, artefatos, documentos, impressões, recortes, anotações, lembranças, fotos e sons em partes e pedaços (muitos pedaços) ... Só o mal avisado pode pensar que isso é uma atividade neutra".

E retornando a DaMatta (1978, p. 27):

não há dúvida de que todo o anedotário referente às pesquisas de campo é um modo muito pouco imaginativo de depositar num lado obscuro do ofício os seus pontos talvez mais importantes e mais significativos. . . um modo muito envergonhado de não assumir o lado humano e fenomenológico da disciplina, com um temor infantil de revelar o quanto vai de subjetivo nas pesquisas de campo, temor este que é tanto maior quanto mais voltado está o etnólogo para uma idealização do rigor nas disciplinas sociais.

A viagem de campo a Montevideo teve um significado especial. Estendeu e aproximou ainda mais os sentidos de campo e tema da pesquisa, como discute Spink (2008). Significou presenciar o fenômeno-foco da pesquisa longe dos espaços do grupo e nas ruas da minha cidade. Ali a nativa era a pesquisadora ${ }^{16}$. Com enorme satisfação (e algum assombro) me vi apresentando a cidade, os códigos e os ritos do lugar às visitantes, que me conferiram a credencial de "tradutora".

Outra viagem de campo nos levou à Espanha. Estivemos ali uma semana, alojadas na casa de um encantador casal de longa militância. E junto de companheiros da economia solidária da Bolívia e da Nicarágua, todos forasteiros naquele campo, palmilhamos os espaços de trabalho, de educação e de luta da Catalunha.

16 Nasci em Montevideo, Uruguay. Na tese constam mais informações sobre as viagens de campo (Andrada, 2013). 
Ao final, os dias pareceriam semanas e o mundo, menor. Não pela longa viagem, mas por reconhecer tão longe de casa os mesmos fenômenos, os reflexos de uma mesma humanidade que resiste. A crise econômica aproximou o novo-sul do velho-norte que, vislumbravam uma direção comum: quando a crise é econômica a saída só pode ser política "y desde abajo".

Por último, onde tudo começou: estive em Porto Alegre, sede da Justa Trama e da Cooperativa Univens (coletivo fundador da rede e cenário da pesquisa anterior), três vezes durante o campo. Embora reconhecesse aqueles ares, as incursões ganharam a perspectiva de estar ali agora em companhia das trabalhadoras dos outros coletivos. Agora o grupo era não apenas maior como outro: às costureiras gaúchas uniram-se em rede os agricultores cearenses e mato-grossenses, as artesãs de longe (Porto Velho) e de perto (Porto Alegre), as companheiras mineiras e catarinenses.

Tantas incursões diferentes guardam uma semelhança: se a pesquisadora se deslocava para longe do seu território, as trabalhadoras da Justa Trama faziam o mesmo. A cada viagem (exceto a primeira), outras integrantes da rede haviam viajado para ali se reunir. Ao lado da minha mala estavam as delas. Também sentiam saudades de casa e curiosidades com o lugar. Além de compartilhar remédios ou pasta de dente, trocávamos impressões como viajantes que éramos. Era comum, portanto, o nativo de uma viagem ser o forasteiro em outra.

Outro fenômeno curioso atinente à pesquisa: por mais tempo que estivesse em campo, era comum chegar e perceber que conhecia apenas parte dos presentes. A outra parcela do grupo era nova para mim. Esse fato ocasionou demandas excedentes: voltar a apresentar a cada incursão a mim e à pesquisa, e a incômoda sensação de estar sempre "entrando em campo", mesmo após um ano de trabalho.

E, assim, ora pensava que estávamos todas em campo; ou que as trabalhadoras traziam o campo junto com elas; que tudo aquilo era um grande campo ou grandes campos, no plural. O que queremos destacar é a ideia de que campo, pesquisadora e pessoas da situação pesquisada pareciam fora de seus lugares tradicionais, em permanentes deslocamentos. Essa impressão aderiu às reflexões sobre as experiências como algo muito significativo ${ }^{17}$.

\section{Quando o campo é plural e itinerante: aparte sobre etnografia multissituada}

Como vimos, os coletivos da Justa Trama não estão reunidos num único e contínuo território. Esse fato, aliado à adoção da etnografia como referencial metodológico, nos

17 Os resultados da pesquisa foram organizados em Casos sobre o cotidiano (com base na experiência etnográfica) e Narrativas sobre a história da rede (amparadas nas entrevistas). A filosofia da vida cotidiana de Agnes Heller (2008) foi o referencial teórico do estudo. A rede revelou-se dialeticamente como organização de trabalho e organização política de resistência. Concluiu-se ainda que a política, no cotidiano da autogestão da rede, pode ser entendida como trabalho. E o trabalho pode ser tomado como objeto de prática política das trabalhadoras (Andrada \& Sato, 2014). colocou um desafio: como fazer etnografia quando o campo é plural e itinerante? Nesse processo, o encontro com a proposta da etnografia multissituada ${ }^{18}$, divulgada por George Marcus (2001, 2004), foi um importante achado ${ }^{19}$.

Tradicionalmente os estudos etnográficos baseiam-se na imersão intensa e prolongada numa única localidade, desde a clássica mise-en-scène malinoswskiana. Ao mesmo tempo, também segundo a perspectiva tradicional, o etnógrafo recorre a outros métodos e técnicas para estabelecer relações entre a situação pesquisada e seus contextos, como a consulta a arquivos documentais e a obras de "teóricos do macro" (Marcus, 2001).

Há outros modos menos usuais de empreender etnografias. A etnografia multissituada, por exemplo, foi formalmente proposta por Marcus (2001) nos anos 1990, mas é praticada por diversos estudiosos das ciências sociais há décadas, como Pierre Bourdieu (Wacquant, 2006) ${ }^{20}$. Em suma, postula a saída do pesquisador de uma dada situação local para seguir objetos localizados num tempo-espaço difuso (Marcus, 2001, p. 111): "esta clase de investigación define para si un objeto de estudio que no puede ser abordado etnograficamente si se permanece centrado en una sola localidad intensamente investigada".

Conforme Teresa Fradique (2003), o modelo permite deslocar-se de um paradigma assente num único lugar de investigação para o exame de territórios com múltiplos ancoramentos, na tentativa de encontrar as expressões de certos objetos de estudo. Essa etnografia móvel ganhou visibilidade nas últimas décadas por representar um potente recurso diante de desafios empíricos contemporâneos, próprios de um mundo mais globalizado e fragmentado. Certamente, as novas formas de ocupação do espaço e do tempo na modernidade avançada provocaram a releitura de tradicionais objetos da antropologia, como territorialidade, diversidade e identidade cultural (Fradique, 2003; Sciré, 2009). Para muitos etnógrafos da antropologia crítica, esses fenômenos exigiram reinventar os modos tradicionais de fazer pesquisas de campo (Marcus, 2001).

Por certo, etnografias multissituadas têm sido desenvolvidas também a partir dos conceitos clássicos da antropologia, como nas vertentes marxistas da disciplina ligadas à economia e à história. Mas se tornaram mais

18 Devemos a referência à etnografia multissituada e sua relação com a pesquisa ao Prof. Magnani (FFLCH/USP).

19 Expoentes da antropologia crítica ou pós-moderna, Clifford e Marcus (1986) escreveram Writing culture: the poetics and politics of ethnography, obra icônica do movimento. Dirigidas a aspectos tradicionais da prática etnográfica, como os modos naturalistas de representação do Outro e a autoridade inconteste do etnógrafo, as críticas propostas alicerçaram formas não eurocêntricas de alteridade, baseadas em postulados como a reflexividade e a cumplicidade (Marcus, 1995).

20 Loïc Wacquant (2006, p. 21) recorda os primeiros estudos de Pierre Bourdieu, desenvolvidos concomitantemente na Cabília (Argélia colonial) e em sua aldeia natal, Béarn (sudoeste da França), e afirma: “. . . Bourdieu pode ser encarado como um precursor ímpar da etnografia multissituada, décadas antes desta ser identificada como um gênero metodológico distinto". O autor também aponta diferenças entre as concepções de etnografia multissituada contemporânea e a utilizada por Bourdieu nos anos 1960. 
frequentes nos anos 1980 e 1990 em projetos de objetos multidisciplinares, como aqueles que tratam das expressões artísticas em contextos urbanos, dos meios de comunicação e dos processos migratórios (Marcus, 2004).

Porém, segundo o mesmo autor, os desafios postos ao imaginário da pesquisa etnográfica tradicional também se relacionam com o que chamou de "autoestima da antropologia":

O problema fundamental aqui é confrontar a política de conhecimento, que qualquer objeto de pesquisa de campo envolve, e a tentativa do etnógrafo de marcar posição em relação a esta política, fazendo do próprio lugar parte do plano de investigação da pesquisa de campo. Assim, desde os anos 80, qualquer antropologia crítica merecedora do nome não apenas tenta falar a verdade ao poder - poder como conceitualizado e teorizado; verdade como subalterna e entendida no interior da vida cotidiana de pessoas comuns observadas de perto -, mas também tenta entender o poder e suas agências, nos mesmos termos etnograficamente empenhados e nas mesmas fronteiras de pesquisa de campo nas quais o subalterno está incluído. . . . isso é o que mais conta na luta para tornar a pesquisa de campo contemporânea mais multilocalizada e política. (Marcus, 2004, pp. 150-151)

Conforme Marcus (2001) e Sciré (2009), o pesquisador interessado em compreender mudanças sociais e culturais locais relacionadas a outros âmbitos, deve se dedicar ao uso de estratégias que lhe permitam ultrapassar o local e as fronteiras e promover conexões em escalas etnográficas distintas. Para tanto, Marcus (2001) define pelo menos seis técnicas, compreendidas como práticas construidas por meio do movimento e rastreio em diferentes cenários de um fenômeno cultural complexo: seguir as pessoas; seguir os objetos; seguir a metáfora; seguir a trama, história ou alegoria; seguir a vida ou a biografia; e seguir o conflito.

Atualmente, a proposta da etnografia multissituada pode gerar ansiedade entre os etnógrafos: preocupações com os limites da etnografia e com a aparente redução do poder do trabalho de campo, segundo Marcus (2004). Ele argumenta que na maior parte das etnografias já se atravessa muitas localidades no trabalho de campo e, portanto, as concepções de campo e trabalho de campo deveriam pressupor potencialmente uma liberdade maior de movimento do pesquisador pelo espaço de sua empiria: "as normas de pesquisa de campo precisam ser libertadas do enfático e vigoroso estar lá do imaginário clássico" (Marcus, 2004, p. 149).

Desde a psicologia social, Peter Spink (2003, p. 28) também discute a concepção de campo como um "complexo de redes de sentidos que se interconectam". Nesse sentido, o autor afirma que se trata de um espaço criado, ainda que involuntariamente, já que o pesquisador terá que debatê-lo e negociá-lo para inserir-se em suas "teias de ação": "Campo portanto é o argumento no qual estamos inseridos; argumento este que têm múltiplas faces e materialidades, que acontecem em muitos lugares diferentes" (Spink, 2003, p. 28).

Assim, mesmo que consideremos inspiradores os aportes da etnografia multissituada, entendemos que não é preciso estar sob seu enquadre metodológico para orientar-se com liberdade e sagacidade em campo e ali seguir o rastro das expressões de nossos objetos. O estudo psicossocial sobre feira livre de Leny Sato (2007, p. 98) é um belo exemplo:

Apreender a rede de relações sociais que configura a feira livre demandou seguir os fios e identificar os "nós" que tecem sua organização. . . . Nessa rede, os fluxos de interação simbólica não estão norteados por um centro a partir do qual emanam as informações, os motes das conversas e as decisões. Os "fios" que ligam as pessoas entre si estendem-se em diversas direções. A estrutura da rede de relações sociais e de significados pôde ser apreendida, mas a posteriori (Mayer, 1966/1987). A rede abriga e é construída pela presença de várias lógicas que se encontram em um lugar, em um dia da semana e se espalham em várias outras feiras livres nos outros dias e em outros lugares.

\section{Apontamentos finais}

Propusemo-nos a discutir aqui alguns efeitos do uso do referencial teórico-metodológico da etnografia em pesquisas psicossociais, tomando para isso o caso de uma pesquisa de campo desenvolvida nessa interface. Por meio da exposição do fazer cotidiano da investigação e seus impasses, tão determinantes de seus resultados e identidade, esperamos ter contribuído para a defesa da centralidade das questões de método quando se trata de fazer e debater pesquisas, especialmente as chamadas pesquisas de campo.

Com efeito, para manter-me junto do objeto - os fenômenos políticos da autogestão cotidiana da Justa Trama - tive que me deslocar por diferentes sítios, materiais e simbólicos, não apenas pelos diversos empreendimentos da rede, geograficamente distantes entre si. Foi preciso circular também pelo campo ampliado conformado pelos circuitos de ações e interesses das trabalhadoras, que vão ao encontro de seus parceiros políticos, nacionais e internacionais, em diversos espaços e fóruns da economia solidária. Nesse sentido, a qualidade ética das relações estabelecidas em campo revelou-se uma condição fundamental para assegurar o bom andamento das experiências, tanto da pesquisa em si quanto do vivido, em geral. Assim, entendemos que o diálogo com a antropologia, especialmente a perspectiva da etnografia multissituada, trouxe contribuições relevantes para o desenvolvimento da pesquisa em psicologia social que, em parte, tratamos de apresentar. 


\section{The method at the center: field notes of a psychosocial research from an ethnographic perspective}

Abstract: The article aims to discuss some effects of the use of the ethnography theoretical-methodological reference in social psychology research, especially the multi-sited ethnography. For this purpose, it takes the case of a doctoral research developed in this interface and discusses some of their issues and contretemps, as well as the choices and resources used to address them. It also seeks to present the criteria that guided the research design in general terms.

Keywords: social psychology, ethnographic method, multi-sited ethnography, methodology, fieldwork.

\section{La méthode dans le centre : les rapports sur le terrain d'une recherche psychosociale de perspective ethnographique}

Résumé: L'article vise à discuter des effets de l'utilisation du référentielle théorique-méthodologique de l'ethnographie dans la recherche sur la psychologie sociale, en particulier l'ethnographie multi-située. Pour ce faire, on prend le cas d'une recherche doctorale développé dans cette interface et on discute une partie de leurs problèmes et inattendue, aussi que les choix et les ressources utilisées pour y remédier. Elle vise également à présenter les critères qui ont guidé le dessin de la recherche d'un mode générale.

Mots-clés: psychologie sociale, méthode ethnographique, ethnographie multi-située, méthodologie, travail sur le terrain.

\section{El método en el centro: relatos de campo de una investigación psicosocial de perspectiva etnográfica}

Resumen: El artículo tiene por objetivo debatir algunos efectos del uso del referencial teórico-metodológico de la etnografía en investigaciones de psicología social, en especial, la etnografía multilocal. Para ello, toma el caso de una investigación de doctorado desarrollada en dicha interfaz y discute parte de sus problemas e imprevistos, como también las opciones y recursos utilizados para enfrentarlos. También busca presentar los criterios que orientaron el diseño de la investigación de manera general.

Palabras clave: psicología social, método etnográfico, etnografía multilocal, metodología, trabajo de campo.

\section{Referências}

Andrada, C. F. (2009). O encontro da politica com o trabalho: um estudo psicossocial sobre a autogestão das trabalhadoras da Univens. Porto Alegre: Abrapso Sul.

Andrada, C. F. (2010). Etnografias em Psicologia Social: notas sobre uma aproximação fecunda. Ponto.Urbe (USP), 7(1), 129.

Andrada, C. F. (2013). Trabalho e política no cotidiano da autogestão: o caso da rede Justa Trama (Tese de Doutorado). Programa de Pós-Graduação em Psicologia Social, Instituto de Psicologia, Universidade de São Paulo, São Paulo.

Andrada, C. F., \& Sato, L. (2014). Trabalho e política no cotidiano da autogestão: a rede Justa Trana. Psicologia \& Sociedade, 26, 3-13.

Becker, H. S. (1999). Métodos de pesquisa em ciências sociais. São Paulo, SP: Hucitec.

Bosi, E. (2003). O tempo vivo da memória: ensaios de psicologia social. São Paulo, SP: Ateliê Editorial.

Clifford, J., \& Marcus, G. E. (1986). Writing culture: the poetics and politics of ethnography. Berkeley, USA: University of California Press.
DaMatta, R. (1978). O oficio do etnólogo ou como ter "Antropological Blues". In E. Nunes. (Org.), A aventura sociológica (pp. 23-35). Rio de Janeiro, RJ: Zahar.

Dicionário etimológico. (2008). Método. Recuperado de https://goo.gl/LJiEPj

Farr, R. M. (1998). As raízes da psicologia social moderna (1872-1954). Petrópolis, RJ: Vozes.

Fonseca, C. (1999). Quando cada caso não é um caso: pesquisa etnográfica e educação. Revista Brasileira de Educação, 10, 58-78.

Fradique, T. (2003). Fixar o movimento nas margens do rio: duas experiências de construção de um objecto de estudo em terreno urbano em Portugal. In G. Velho \& K. Kuschnir (Orgs.), Pesquisas urbanas: desafios do trabalho antropológico (pp. 99-117). Rio de Janeiro, RJ: Zahar.

Geertz, C. (1999). O saber local: novos ensaios em antropologia interpretativa. Petrópolis, RJ: Vozes.

Gonçalves Filho, J. M. (1998). Humilhação social - um problema político em psicologia. Psicologia USP, 9(2), 11-67. 
Heller, A. (2008). O cotidiano e a história. São Paulo, SP: Paz e Terra.

Magnani, J. G. C. (1997). O (velho e bom) caderno de campo. Revista Sexta-Feira, 1(1), 8-12.

Magnani, J. G. C. (2009). Etnografia como prática e experiência. Horizontes Antropológicos, 15(32), 129-156.

Marcus, G. E. (1995). Ethnography in/of the Word System: The Emergence of Multi-Sited Ethnography. Annual Review of Anthropology, 1(24), 95-117.

Marcus, G. E. (2001). Etnografía en/del sistema mundo. El surgimiento de la etnografía multilocal. Alteridades, 11(22), 111-127.

Marcus, G. E. (2004). O intercâmbio entre arte e antropologia: como a pesquisa de campo em artes cênicas pode informar a reinvenção da pesquisa de campo em antropologia. Revista de Antropologia, 47(1), 133-158.

Mello, S. L. (1988). Trabalho e sobrevivência: mulheres do campo e da periferia de São Paulo. São Paulo, SP: Ática.

Nespolo, N. I. F. (2014). Tramando certezas e esperanças: a história não para. São Leopoldo, RS: Oikos Editora.

Oliveira, R. C. (2000). O trabalho do antropólogo. São Paulo, SP: Unesp.

Rodrigues, A. M. (1978). Operário, operária - estudo exploratório sobre o operariado industrial da Grande São Paulo. São Paulo, SP: Símbolo.

Santos, B. S. (2002). A crítica da razão indolente. Contra o desperdício da experiência. Porto, PT: Afrontamento.

Sato, L. (2007). Processos cotidianos de organização do trabalho na feira livre [Edição especial 1]. Psicologia \& Sociedade, 19, 95-102.
Sato, L. (2009). Olhar, ser olhado e olhar-se: notas sobre o uso da fotografia na pesquisa em psicologia social do trabalho. Cadernos de Psicologia Social do Trabalho, 12(2), 217-225.

Sato, L., \& Souza, M. P. R. (2001). Contribuindo para desvelar a complexidade do cotidiano através da pesquisa etnográfica em psicologia. Psicologia USP, 12(2), 29-47.

Schmidt, M. L. S. (2008). Pesquisa participante e formação ética do pesquisador na área da saúde. Ciência \& Saúde Coletiva, 13(2), 391-398.

Sciré, C. O. (2009). Uma etnografia multissituada das práticas populares de consumo. Plural, 16(1), 93-109.

Silva, V. G. (2006). O antropólogo e sua magia: trabalho de campo e texto etnográfico nas pesquisas antropológicas sobre as religiões afro-brasileiras. São Paulo, SP: Edusp.

Singer, P. (2002). Introdução à economia solidária. São Paulo, SP: Fundação Perseu Abramo.

Spink, M. J. P. (2007). Pesquisando no cotidiano: recuperando memórias de pesquisa em psicologia social. Psicologia \& Sociedade, 19(1), 7-14.

Spink, P. K. (2003). Pesquisa de campo em psicologia social: uma perspectiva pós-construcionista. Psicologia \& Sociedade, 15(2), 18-42.

Spink, P. K. (2008). O pesquisador conversador no cotidiano [Edição especial]. Psicologia \& Sociedade, 20, 70-77.

Wacquant, L. (2006). Seguindo Pierre Bourdieu no campo. Revista de Sociologia e Politica, 26(1), 13-29.

Recebido: $22 / 02 / 2017$

Aprovado: 20/03/2018 